\title{
Micro, Small and Medium Enterprises' External Financing Challenges: The Role of Formal Financial Institutions and Development Finance Intervention in Tanzania
}

\author{
Nyankomo Marwa
}

\begin{abstract}
Micro, Small and Medium Enterprises (MSMEs) play a significant role in income generation, job creation, poverty reduction and reducing income inequality. However, MSMEs from developing countries are exposed to several challenges in their business operations. Among others, access to external financing has been cited to be the most pressing challenge for MSMEs in developing economies and Tanzania in particular. Using a desk review methodology, this paper explores in detail the causes of the problem and mechanisms currently put in place to address these. Briefly, the paper delineates how the structural mismatch between mainstream funding requirements and unique characteristics of MSMEs has led to market failure. It further provides insights on innovative financing strategy, which may be a better alternative to circumvent the problem.
\end{abstract}

Index Terms-MSMEs, financial institutions, development finance, Tanzania.

\section{INTRODUCTION}

Micro, small and medium enterprises (MSMEs) play a significant role in job creation, poverty reduction and reducing inequality in both developed and developing economies. MSMEs create approximately $80 \%$ of new jobs in Canada; employ about $40 \%$ of the labor force and account for more than $63 \%$ of the GDP in developing countries [1], [2]. In Tanzania, the sector employs over 33\% of the labor force. When taking the informal sector together with the formal sector, the total contribution of the sector to GDP is about $63 \%$ [3]. Moreover, about 700,000 job seekers enter the labor market each year. The formal sector absorbs only 40,000 annually. The implication is that the remaining excess annual labor supply of about 660,000 are absorbed by MSMEs or left unemployed [3]. Based on these statistics, the role of MSMEs in Tanzania cannot be over-emphasized.

Despite the crucial role played by MSMEs in employment creation, poverty reduction and fostering economic growth in both urban and rural areas, they still face many challenges. Among others, access to finance has been mentioned to be top most by many MSMEs [4]-[9]. Given the commercial orientation of the conventional financial system, it may not be surprising to see that banks are not lending to MSMEs.

Manuscript received February 1, 2013; revised March 31, 2014.

The author is with University of Stellenbosch Business School (AACSB, EQUIS, AMBAs), South Africa (e-mail: nyankomo.marwa@gmail.com).
This is because MSMEs are risky in nature (either perceived or real or both), small in size, have high transaction costs per service and may lack transparency in their operations. Therefore, reckless lending to this market segment may jeopardize the core business of the formal banking system. Despite the abovementioned challenges, the importance of the sector to any developing economy necessitates a concerted effort in addressing the observed market failure. However, such interventions call for a more innovative and alternative financing mechanism that is better suited for MSMEs. As part of the solution, the recent resurgence of development finance institutions including microfinance has played a key role as an alternative financing mechanism in this market segment.

Surprisingly little has been done to explore the role played by development finance interventions in addressing the existing market failure in the formal financial system. To bridge the existing gap, this study employs desk review methodology to: characterize MSMEs in the Tanzanian economy, explore the extent of formal financial institutions in financing MSMEs and their limitations, and discuss existing development financing interventions and the challenges facing these institutions. Such knowledge will provides further insights about the role and challenges of development finance interventions in increasing access to finance for MSMEs.

\section{The CONCEPTUAL AND TEChNiCAL DEFINITIONS OF MSMES}

Globally, there is no universally accepted definition of MSMEs; however, most definitions are composed by either the number of employees and/ or capital requirement as a classification factor. The existing divergence of definitions among intergovernmental agencies and different governments is far less than scientific [10]. For example, the World Bank defines a SME as a firm with 300 employees or maximum revenue of $\$ 15,000,000$. The UNDP defines SMEs as firms with a maximum of 200 employees, while the African Development Bank uses a threshold of 50 employees. In Vietnam, SMEs have a maximum of 300 employees, while MSMEs in China can have as many as 3000 employees. In Norway, the threshold for SMEs is 100 employees [10].

It would be expected that the definition of MSMEs may vary according the level of country development, which is true in some cases, but by the evidence presented in Section II 
we see significant contradictions. These contradictions complicate the cross-country comparisons and may lead to ineffective international aid or development intervention targeting. Gibson and Van der Vaart offer extensive debate and discussion around the irregularity of MSME definition and policy implications [10]. They conclude by proposing a tentative definition of a SME as "a formal enterprise with annual turnover, in U.S. dollar terms, of between 10 and 1000 times the mean per capita gross national income, at purchasing power parity, of the country in which it operates". While this definition does not solve the problem completely, there is somewhat more harmonization for cross-country studies.

The existing heterogeneity of MSME definitions globally necessitates country-specific definitions tailored to local environments. For example, by using the World Bank definition in Tanzania, almost all enterprises will fall under the category MSMEs. Accordingly, the government of Tanzania has its own definition of MSMEs stated in MSMEs policy document of 2002. It uses the number of employees and/ or total number of assets as parameters in its nomenclature of MSMEs. MSMEs are grouped as non-farm economic activities in manufacturing, services, commerce and mining. The classification defines micro enterprises as those organizations "engaging up to 4 people, in most cases family members or employing capital amounting up to Tshs 5 million. The majority of micro enterprises fall under the informal sector. Small enterprises are mostly formalized undertakings engaging between 5 and 49 employees or with capital investment from Tshs 5 million to Tshs 200 million. Medium enterprises employ between 50 and 99 people or use capital investment from Tshs 200 million to Tshs 800 million" [11]. Where the capital versus labor threshold contradicts each other, the asset-based definition will be considered.

\section{CHARACTERISTICS AND EXTENT OF MSMES IN TANZANIA}

Most MSMEs are labor intensive, relatively easy to start and are widely distributed across the country, including rural and urban areas. They play a significant role in job creation, income generation, poverty alleviation and reducing income inequality [12]. Recent statistics show that at least 700,000 new recruits enter the job market every year. With the formal sector employing only 40,000, the remainder is left for self-employment, unemployment or being employed by MSMEs. Most of the 700000 job seekers are school leavers with limited marketable skills, which has significant implications for the level of education and skills dominant in MSMEs. Globally, MSMEs have played a significant role in economic and community development. In the USA, they represent about $33 \%$ of domestic revenue and sales [13], while in European Union they account for about $66 \%$ of total employment [14]. In Tanzania, MSMEs account for approximately $33 \%$ of total employment and about $35 \%$ of total GDP [2], [11]. Despite the important role played by MSMEs, the sector faces significant financing challenges because of the inherent characteristics of their business practices and operating environment. The next section provides a brief description of the characteristics of MSMEs in Tanzania and how these impact on their access to finance.

\section{A. Size, Managerial Skills and Ownership Structure}

As shown clearly in section two, most MSMEs are small in size and operate outside the formal economy, especially those at the bottom of the pyramid of MSMEs. These mainly operate as family-based enterprises with no clear demarcation between family and business assets. Most of them have limited contractual arrangement with their suppliers and customers and no formalized lease ownership for the land or premises they are operating from. This makes their ability to meet the collateral requirement by banks extremely difficult. Employees often have limited managerial skills and there is heavy reliance on the available family labor to run the business, which constrains the business from long-term growth and expansion.

\section{B. Poor Record Keeping, Limited Business Skills and Information Opacity}

Most MSMEs suffer from a lack of, or poor, record-keeping systems and undocumented business processes and contracting. They rely heavily on operators' memory and a trust-based business traction system. While such a system may have its own advantage in terms of cost saving and decreasing transaction costs, monitoring and evaluation by third parties is rendered almost impossible. Most of these businesses suffer from inappropriate or incomplete business process records and other key information, which leads to information opacity [15]-[18]. Consequently, it becomes extremely difficult to distinguish businesses that are performing well from those thriving business, from a third party perspective. As a result, the information opacity leads to an unexpected barrier to financial access from formal banking institutions.

\section{Weak Regulation and Lack of Property Rights}

The regulatory system and institutional support in Tanzania is weak, particularly in terms of land registration and ownership types. Most of the land in the country is owned as communal property and a limited amount has been surveyed and registered to high income groups. The administrative hurdles and cost implications of land registration are cumbersome and may deter many MSMEs from going this route. As result, most MSMEs are operating from communally- or family-owned land and premises, which is another problem related to the lack of appropriate collateral required by formal financing institutions.

In summary, the characteristics of MSMEs as discussed above are self-defeating in terms of financial access from mainstream banking systems. This is explained by the fact that formal banking is mainly represented by financial intermediaries mobilizing funds from net savers to net borrowers. In order for the banks to remain sustainable and profitable, it may not be acceptable to take unwarranted risks by lending their fund to organizations with high levels of information opacity and a high probability of default due to foreclosure or other reasons. Hence there is a need for MSME managers, policy makers and other interested stakeholders to focus on alternative financing mechanisms in addressing the resulting market failure due to structural mismatches between 
the formal financial system and MSMEs.

\section{CHARACTERISTICS OF FORMAL FINANCIAL}

INSTITUTIONS IN TANZANIA, THEIR ROLE IN ECONOMIC DEVELOPMENT AND LIMITATIONS IN FUNDING MSMES

The classification of formal versus informal financial institution is based on the extent to which an institution is exposed to regulation by the responsible monetary authorities. The informal financial institution covers organizations that are not regulated by monetary authorities or any other public authority and work with a low degree of formalization of their transactions [19]. On the other hand, formal financial institutions cover financial intermediaries that are recognized by the government and are regulated by law under the monetary authorities' supervision. In the context of Tanzania, these institutions include commercial banks and non-banking institutions. The Dar Es Salaam stock exchange also falls into the category of formal financial institutions. This section discusses in detail the characteristics of formal financial institutions in Tanzania and the extent of their ability to extend financial services to MSMEs.

In theory, financial institutions are expected to play a significant role in economic development through saving mobilization and efficient resource allocation by channeling surplus funds to the deficit side. The efficient resource mobilization and reallocation enables needy firms and enterprise to access funds to upscale, start new businesses or buy new technology, which is expected to have a positive impact on economic growth and development [20]-[22]. The extent to which the financial institution leads to economic development remains a contentious debate that is not yet settled. For example, while the bank-based system seems to have worked in Japan and Germany to promote economic growth, Africa is still lagging behind in spite of the dominance of the bank-based financial system on the continent. The discrepancy in expected outcome may signal that there is a minimum threshold of supporting environment and preconditions that need to be in place in order to release the full gains from financial institutions.

Historically, financial institutions in Tanzania were highly controlled and were state-owned until the 1980s. After financial liberalization in the 1990s, most of these were privatized and the country started to see new foreign banks entering the market. Before liberalization, there were only three banks (National Bank of Commerce, CRDB bank and Postal bank) serving almost all regional administrative headquarters and selected districts' headquarters. The three banks were widespread in terms of branches across the country. Despite this, the majority of the population was not covered. It was estimated that only $11 \%$ of the population had access to the formal banking sector in Tanzania [23]. However, after financial liberalization there has been a significant influx of foreign and local banks in the financial market. The current figures from the Bank of Tanzania show that there are approximately 32 commercial banks under its regulations and over 18 non-banking financial institutions.
The main challenge for commercial banks is that they all located in big cities and urban centers due to the availability of infrastructure and a large concentration of the customer base. This leaves most people living in rural areas unsaved by default. Furthermore, the lending principles used by commercial banks are based on due diligence and the client needs to be closely scrutinized. As part of the process, the borrower needs to disclose information about his/ her business, including the balance sheet and sales record for the past 6 months or more. Commercial banks may also require that the business should be in operation for more than one year in most cases, be registered and have a business plan. Some banks even require that the business should be within a $5 \mathrm{~km}$ radium from their bank branch [3], [15], [16].

There is thus a significant mismatch between MSME business practice, operations and characteristics and what is required to obtain a loan from a commercial bank. This is probably the biggest hurdle that needs the most attention. It is unsurprising then that formal financial institutions fund less than $1 \%$ of the total demand of about the approximately $8,000,000$ MSMEs countrywide [24]. Based on the statistic above, it is evident that the credit market in Tanzania is far from being perfect and that MSMEs are among the most vulnerable, since the banking sector does not seem to meet their financing requirement.

Security markets may be considered as an alternative form of accessing external financing for MSMEs. Unfortunately, the security market in Tanzania is in its infant stage and very shallow. The procedural requirements for a company to be listed are also beyond the reach for most MSMEs.

As discussed above, the conditions required by formal financial institutions to access credit are not favorable to most MSMEs. In fact, almost all the microenterprises and most SMEs in the informal sectors are excluded by the conditionality. Banks essentially ask what MSMEs are not able to provide within the acceptable time limit. In summary, the nature and characteristics of MSMEs and their inability to attract external financing from formal financial institutions is a structural problem. In most cases, the failure of commercial banks and other formal financial institutions to fund MSMEs is based on valid and legitimate concerns. In other words, a well-functioning financial system may have resulted in market failure due to inherent administrative costs and information problems when dealing with MSMEs. Such a market failure limits MSMEs' in several ways including: capacity to survive, potential for expansion, technology upgrade, expand their markets, improve management, raise productivity and eventually increase incomes [11]. The quotation below from the National MSMEs policy illustrates these challenges more clearly [11].

"The SME sector in Tanzania has limited access to finance due to the following factors: the sector is perceived as a high risk one; inability of the SME operators to fulfill the collateral requirements; most banks do not operate an SMEs financing window; some of the banks operate in limited geographical areas; inexperience of Bank Staff in issues related to Micro-finance; lack of a guarantee scheme to back up banks financing SMEs; high cost of screening and administering small loans spread over big areas and 
inabilities of borrowers to prepare and present applications that meet [the] bank's requirements".

The next section explores the efforts which have been taken by the government, entrepreneurs and other stakeholders in response to the existing market failure in the formal financial sector.

\section{DEVELOPMENT FINANCE INTERVENTIONS AND CHALLENGES}

Various efforts and approaches have been used to circumvent the problem of market failure and credit rationing in the MSME market segment. The popular approaches are the use of family and friends, money lenders, informal financial institutions, microfinance, government and donor-funded projects. Since family, friends and money lenders are limited in the scope and breadth of financing available; this section will mainly focus on government- and donor-funded interventions, as well as microfinance interventions in the country.

\section{A. Government- and Donor-Funded Interventions}

\section{(Top-down Approach)}

Several efforts have been made by the government in addressing the problem of market failure in the credit market given the role played by the MSME sector in the economy. Some of the programs initiated by the government as development funding mechanisms and schemes include the National Entrepreneurship Development Fund, the Small Entrepreneurship Loan Facility under the Ministry of Finance, the Presidential Trust Fund, the National Income Generating Programme and the National Microfinance Bank [11], [15].

These programs are designed to cater for the financial needs of MSMEs. The problem with the programs is the lack of coordination and high level of fragmentation. These programs are also managed with different ministries and departments, which increases unnecessary coordination and transaction costs. However, the National Economic Empowerment Agency has been designed to be responsible to oversee the programs and coordinate their activities. Despite the government's efforts, the efficacy of these programs is limited mainly due to budgetary constraints, inadequate manpower and limited coverage geographically.

\section{B. Microfinance Interventions (Bottom-up Approach)}

Significant effort has been invested in microfinance as a major funding source for MSMEs. Within the microfinance space, there diverse players but the dominant ones are international microfinance organizations and saving and credit cooperatives. International microfinance players include FINCA, BRAC, Oiko Credit, Opportunity International, Pride Tanzania Limited and the Desjardins group. In total, they are offering savings and credit services to more than 400,000 MSMEs. Another dominant group is savings and credit cooperatives (SACCOS), which comprise over 5500 institutions offering services to over 9,300,000 individuals and business [25].

Microfinance institutions have managed to strive in this lower segment of the economy because of their innovative lending methodology, which is different to that used by commercial banks. Microfinance institutions do not emphasize traditional forms of collateral, but rather rely on trust and group lending methodology as alternative forms of collateral. Furthermore, since these institutions are localized, they counter the information problem because they almost know each member within their locality. Despite the significant growth of microfinance institutions in the country, most, especially SACCOs, suffer from significant liquidity, managerial and operational challenges. According to WOCCU the waiting time for SACCO's credit is high due to liquidity problems and the regulatory framework is virtually nonexistent. The central bank and the ministry of agriculture and cooperatives have commissioned the World Council of Cooperatives to develop a regulatory framework to safeguard members' savings and ensure prudential financial management in SACCOs [25].

In summary, microfinance is playing a significant role in attempting to fill the financing gap resulting from the market failure in the credit market. However, the demand is significantly higher than the supply side. According to recent statistics, only 5\% of MSMEs are able to access credit [24]. Therefore more effort needs to be made to solve the financing hurdle. Another problem is that most of the microfinance market is unregulated and this poses a serious threat to members' savings in case of financial mismanagement and malpractice. Some effort is in place to develop a regulatory framework for regulating SACCOs. More importantly, there is a need to design an innovative bridge that will link microfinance institutions with formal financial institutions to reduce liquidity constraints. Significant efforts have been pioneered by commercial banks, such as CRDB, and pension funds, for example Parastatal Pension Fund (PPF) and National Social Security Fund (NSSF).

\section{CONCLUSION}

MSMEs in Tanzania play a significant role in income generation, job creation and poverty reduction. However, the sector is facing significant credit rationing from e formal financial institutions. As a result, the sector is highly credit-constrained. The credit rationing by formal financial institutions is explained mainly by the mismatch between the requirements of formal financial institutions' lending process and structural problems in MSMEs' business processes. The existing mismatch leads to credit market failure in the MSME market.

In response to this credit market failure, development finance interventions from the government, entrepreneurs and other stakeholders have emerged as alternative financing mechanisms. The most dominant players are microfinance organizations including serving and credit cooperatives, government programs and other non-banking financial institutions. Yet the demand by MSMEs is far outstripping the supply of such finance. Only 5\% of the demand is being met by development finance institutions.

More work need to be done to circumvent the problem of information capacity and link more MSMEs with formal financial institutions to increase the share of external financing. The need for external financing is critical in 
starting up a business, up scaling an existing business, improving managerial skills and buying new technology.

\section{REFERENCES}

[1] SIAST. Program overview. Certificate in entrepreneurship and small business program. [Online]. Available: http://gosiast.com/programs-and-courses/programs/Entrepreneurshipand-Small-Business.aspx

[2] M. Ayyagari, T. Beck, and A. Demirgüç-Kunt, "Small and medium enterprises across the globe," World Bank Policy Paper, 2005.

[3] A. R. Kira, "The evaluation of the factors influencing the access to debt financing by Tanzanian SMEs," European Journal of Business and Management, vol. 5, no. 7, pp. 1-18, 2013.

[4] T. Beck and A. Demirguc-Kunt, "Small and medium-size enterprises: Access to finance as a growth constraint," Journal of Banking \& Finance, vol. 30, issue 11, pp. 2931-2943, 2006.

[5] N. Mori, E. Richard, A. Isaack, and D. Olomi, "Access to finance for SMEs in Tanzania," in African Entrepreneurship and Small Business Development: Context and Process, vol. 1, D. Olomi, Ed. Dar es Salaam: Otme Company Ltd., 2009.

[6] S. Kessy and S. S. Temu, "The impact of training on performance of micro and small enterprises served by microfinance institutions in Tanzania," in Proc. the 10th Annual Conference 2009 IAABD, 2009, pp. 123-126.

[7] T. Beck, "Financing constraints of SMEs in developing countries: Evidence, determinants and solutions," Tilburg University Working Paper No.12-3508403, 2007.

[8] T. Beck and A. Demirguc-Kunt, "Access to finance: An unfinished Agenda," World Bank Econ Rev, vol. 22, issue 3, pp. 383-396, 2008.

[9] ACCA. (2009). Access to finance for small and medium sized enterprise sector: Evidence and conclusion. [Online]. Available: http://www2.accaglobal.com/pdfs/ACCA_CGA_CPA.pdf

[10] T. Gibson, and H. J. Van der Vaart, "Defining SMEs: A less imperfect way of defining small and medium enterprises in developing countries," Brooking Global Economy and Development Institution Working papers Series, September 2008.

[11] URT, Small and Medium Enterprises (SME) Development Policy, 2003.

[12] URT, National Microfinance Policy, 2001.

[13] E. Velasco and E. A. Cruz, "The long and short of it: globalization unraveled," in Bridging the Gap - Philippine SMEs and Globalization, O. M. Alphonso and R. Myrna, Eds. Manila: Small Enterprises Research and Development Foundation, 2001.

[14] European Union, "Directorate-general for enterprise. European charter for small enterprises," 2001.
[15] M. S. Omar, "Financial constraints and structural characteristics of small and medium sized enterprises: the case of Tanzania," Thesis report, Lund University, Sweden, 2008.

[16] N. Mori and E. Richard, "SMES access to financial services: Tanzanian bankers's eye," Chinese Business Review, vol. 11, no. 2, pp. 217-223, 2012.

[17] D. Olomi, M. Chijorig, and N. Mori, "Mapping of obstacles for establishing and expanding business in Tanzania," Dar es Salaam, University of Dar es Salaam, 2007.

[18] D. Olomi, N. Mori, E. Mduma, and G. Urassa, "Constraints to Access to Capital by Tanzanian SMEs," Dar es Salaam: REPOA, 2008.

[19] D. Germidis, D. Kessler, and R. Meghir, "Financial systems and development: what role for the formal and the informal financial sectors?" OECD-Development Centre Studies, Paris, Transaction Publishers, 1991.

[20] J. Schumpeter, "The theory of economic development," New Jersey: Transaction Publishers, 1982.

[21] R. King and R. Levine, "Finance and growth: Schumpeter might be right," Quarterly Journal of Economics, vol. 108, issue 3, pp. 717-737, 1993.

[22] M. J. Aziakpono, "Financial development and economic growth: theory and a survey of evidence," Journal of Studies in Economics and Econometrics, vol. 35, issue 1, pp. 1-30, 20011.

[23] Finscope, "Finscope National Survey on access and demand for financial services in Tanzania," Dar es Salaam: Financial Sector Deepening trust, 2007.

[24] A. Abdal, "Impact on microfinance institutions on growth of micro and small enterprises and owners in Tanzania," 2011.

[25] WOCCU, "Developing regulatory framework for Tanzanian SACCOs," World Council of Cooperative Unions', 2013.

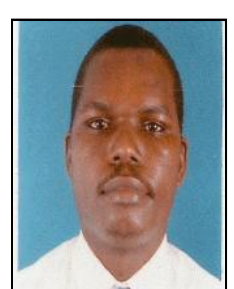

Nyankomo Marwa is a $\mathrm{PhD}$ candidate in development finance and lecturer at the University of Stellenbosch Business School, South Africa and member of the Global Development Finance Association. He holds a PhD ABD in public policy from Johnson Shoyama Graduate School of Public Policy, University of Saskatchewan (Canada), a master's in agricultural economics from the University of Nebraska Lincoln (USA), a master's in applied statistics and biostatics from Hasselt University (Belgium) and a BSc. agricultural economics and agribusiness from Sokoine University of Agricultur, (Tanzania).

He has extensive experience in teaching applied statistics and applied economics and his research focuses on applied economic, development finance, empirical modeling of efficiency and sustainability of financial institutions and biostatistics modeling. 